Supporting Information

\title{
A Label-Free and Sensitive Electrochemical Biosensor for Amplification Detection of Target Nucleic Acids Based on Transduction Hairpin and Three-Leg DNAzyme Walkers
}

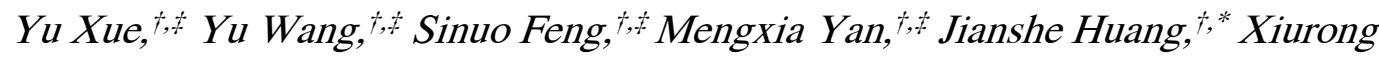

$$
\text { Yang }^{t, t, * *}
$$

$\dagger$ State Key Laboratory of Electroanalytical Chemistry, Changchun Institute of Applied Chemistry, Changchun, Jilin 130022, China

$\ddagger$ University of Science and Technology of China, Hefei, Anhui 230026, China

\footnotetext{
*Fax: +86 431 85689278. E-mail: xryang@ ciac.ac.cn, huangjs@ @iac.ac.cn
} 


\section{Reagents.}

Tris (2-carboxyethyl) phosphine hydrochloride (TCEP), 6-Mercapto-1-hexanol $(\mathrm{MCH})$, methylene blue $(\mathrm{MB})$ and glutaraldehyde $(\mathrm{GA}, 25 \% \mathrm{v} / \mathrm{v})$ aqueous were purchased from Sigma-Aldrich (St Louis, MO, USA). Tris-(hydroxymethyl) aminomethane (Tris) and magnesium chloride hexahydrate $\left(\mathrm{MgCl}_{2} \cdot 6 \mathrm{H}_{2} \mathrm{O}\right)$ were obtained from Sangon Biotechnology Co., Ltd. (Shanghai, China). Other reagents (analytical grade) were all received from Beijing Chemical Regent Co. (Beijing, China) and used as provided. All DNAs, miRNAs and DNA Marker A (25-500 bp) were custom-synthesized by Sangon Biotechnology Co., Ltd. (Shanghai, China), and the sequence of oligonucieotides were listed in Table S1. The binding regions of the complementary sequence were marked with the same colors. The oligonucleotide stock solutions $(50 \mu \mathrm{M})$ were prepared in RNAase-free ultrapure water, which were further diluted to a certain concentration with TNKM buffer $(20 \mathrm{mM}$ Tris-HCl, 140 $\mathrm{mM} \mathrm{NaCl}, 5 \mathrm{mM} \mathrm{KCl}, 20 \mathrm{mM} \mathrm{MgCl} 2, \mathrm{pH}$ 7.5) before use. All the solutions were prepared by ultrapure water from Milli-Q water system with 18.25 M $\Omega$. The human blood serum was provided free of charge by the Second Hospital of Jilin University.

\section{Apparatus.}

Electrochemical characterizations including cyclic voltammetry (CV), electrochemical impedance spectroscopy (EIS), and differential pulse voltammetry (DPV) were carried out on a CHI660A electrochemical workstation (Shanghai $\mathrm{CH}$ Instruments, China). The conventional three electrode system consisted of a 3-mm diameter gold electrode as working electrode, $\mathrm{Ag} / \mathrm{AgCl}(3 \mathrm{M} \mathrm{KCl})$ reference electrode and a platinum wire counter electrode. Dual polarization interferometry (DPI) measurements were performed in real time utilizing DPI instrument (AnaLight Bio200, Farfield Group Ltd., Crewe, U.K.). The operating temperature of DPI was 20 ${ }^{\circ} \mathrm{C}$. Nucleic acid electrophoresis apparatus (WIX-EP 600) was applied for the native polyacrylamide gel electrophoresis (PAGE). The fluorescence experiment was measured on the F-4600 fluorescence spectrophotometer. The X-ray photoelectron spectroscopy (XPS) analysis of the elemental composition on gold electrode surface 
was recorded on Thermo ESCALAB 250 electronic energy spectrometer. AFM images were acquired on a Dimension Edge AFM (Bruker, Germany) in air under tapping mode.

Table S1. All sequences used in experiment.

Name $\quad$ Sequence (5'-3')

TAGAGTTCGACCCCTATCACGATTAGCATTAATCGAA

THP

CTCTACAATCCCTCATCACG

GCGGGTTGGGTTTTTTACTAT/rA/GGAAGAGATTTTTT

SHP

CCCAACCCGCTTTT C6-SH

GCGGGTTGGGTTTTTTACTAT/rA/GGAAGAGATTTTTT

Amino-SHP

CCCAACCCGCTTTTTTTT C6- $\mathrm{NH}_{2}$

H1

TCTCTTCTCCGAGCCGGTCGAAATAGTCCTACAATCC CTCATCACGCAACACTAACCTCGTGATGAGGGATTGT AGAGTTCG

TCTCTTCTCCGAGCCGGTCGAAATAGTATCACGCAAC

$\mathrm{H} 2$ $\underline{\text { ACTAACCTCGAACTCTACAAAGGTTAGTGTTGCGTGA }}$ TGAGGGA

H3

TCTCTTCTCCGAGCCGGTCGAAATAGTTAACCTCGAA CTCTACAATCCCTCATCACGTTGTAGAGTTCGAGGTT AGTGTTG

miRNA 155

UUA AUG CUA AUC GUG AUA GGG GU

miRNA 21

UAG CUU AUC AGA CUG AUG UUG A

miRNA 133a

AGC UGG UAA AAU GGA ACC AAA U 
Single-base matched

UUA AUG CUA AUA GUG AUA GGG GU

miRNA 155

Triplex-base matched

UUA AUA CUA AUA GUG AUC GGG GU

miRNA 155
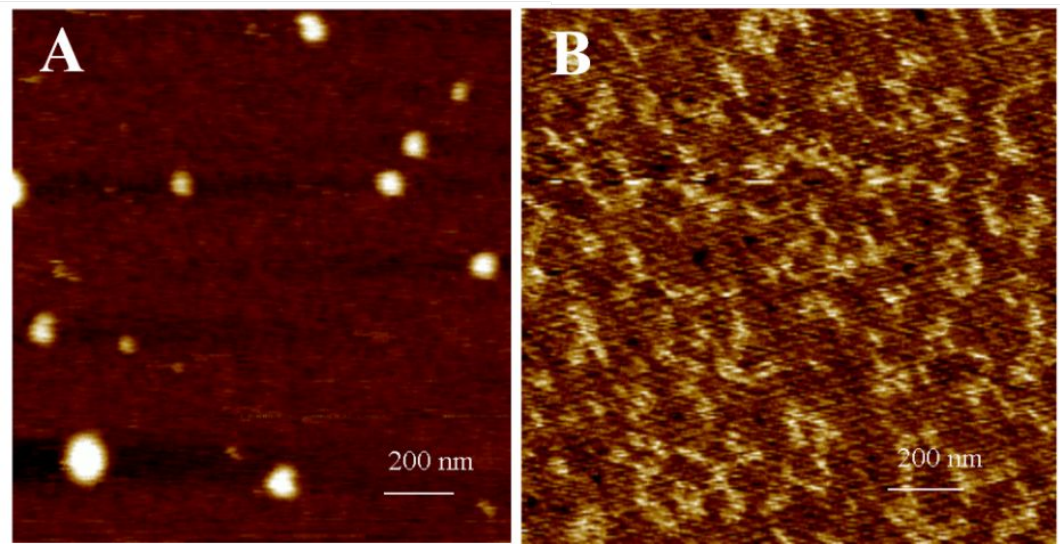

$2.3 \mathrm{~nm}$

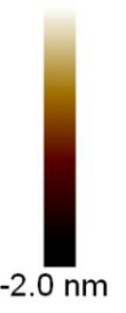

Figure S1. AFM images of the assembly products in the absence (A) and presence (B) of $0.5 \mu \mathrm{M}$ miR-155. The concentration of other components is $5 \mu \mathrm{M}$.

In order to observe the changes of elemental composition on the modified electrode surface, XPS analysis were performed. ${ }^{10}$ As shown in Figure S2, the typical peak of Au4f was presented for the bare GE at $83.69 \mathrm{eV}$ (curve a). After immobilizing SHP and $\mathrm{MCH}$ on the GE successively (curve b), the signal of Au4f decreased dramatically, and the signal for $\mathrm{C} 1 \mathrm{~s}(284.55 \mathrm{eV})$ and $\mathrm{O} 1 \mathrm{~s}(531.79 \mathrm{eV})$ increased obviously. Besides, the characterization peak of N1s emerged at $399.2 \mathrm{eV}$, which originated from the bases of SHP. The results of curve b suggested that the SHP and $\mathrm{MCH}$ were successfully assembled and covered on the GE surface. With the addition of the reaction solution of three-leg DNAzyme walkers to the MCH/SHP/GE (curve c), the binding energy of $\mathrm{C} 1 \mathrm{~s}, \mathrm{O} 1 \mathrm{~s}$ and N1s decreased accompanying with the slightly decreased signals of Au4f. This phenomenon reveals that three-leg DNAzyme walkers could cleave the SHP into two fragments, one part was washed by the buffer 
solutions away the GE surface, and the other retained on the GE surface, which may be lying and covering on the GE surface rending the decreased signal of Au4f. The results of XPS further certified that the successful modification of SHP and MCH on the GE surface and the feasibility of this heterogeneous reaction process on the electrode surface.

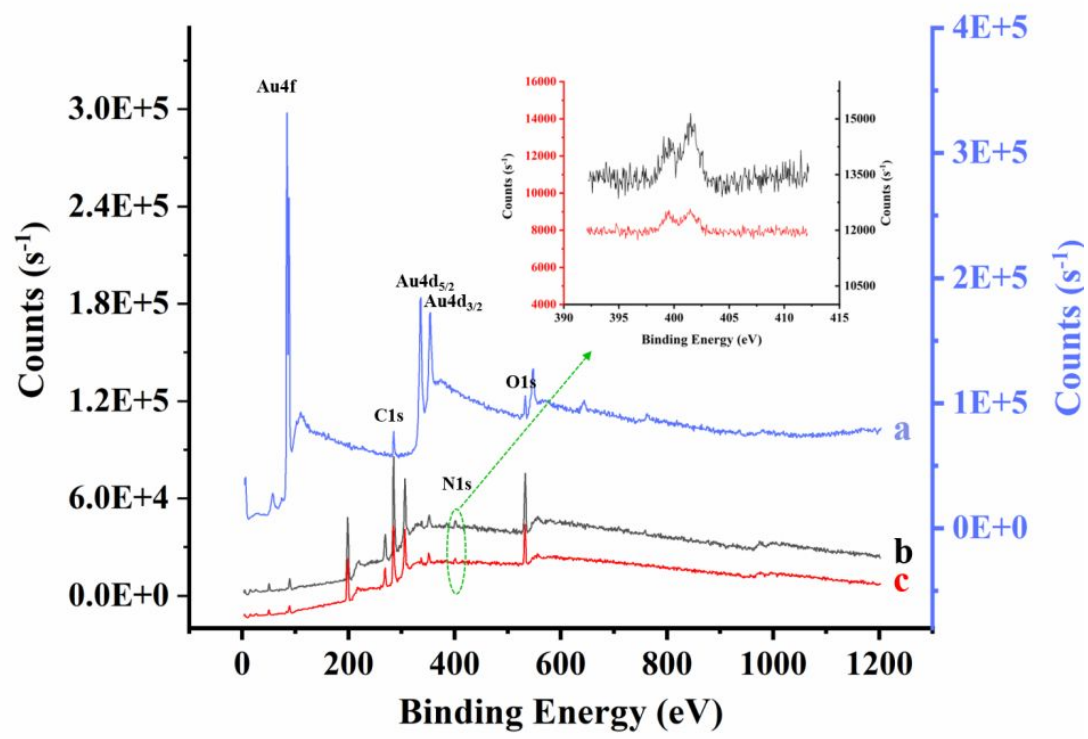

Figure S2. XPS spectra of bare GE (a), SHP and MCH modified GE (b), and the $\mathrm{MCH} / \mathrm{SHP} / \mathrm{GE}$ incubated with three-leg DNAzyme walkers (c). Insert showing the changes of N1s binding energy.

SYBR Green I, an unsymmetric cyanine dye, has very weak fluorescence signal in aqueous solution. Previous reports indicated that the interaction between SYBR Green I and ssDNA is very weak, but a strong affinity exists between SYBR Green I and dsDNA, and the fluorescence intensity of SYBR Green I is significantly enhanced after interaction with dsDNA ${ }^{11}$. Based on the trait of SYBR Green I, Xiang and coworkers $^{12}$ detected the specific single-stranded DNA with molecular beacons and nucleic acid dyes SYBR Green I. Herein, SYBR Green I was selected as the fluorescence probe to evaluate the cleaving activity of three-leg DNAzyme walkers. The results were displayed in Figure S3. Compared to the fluorescence signal of SYBR Green I in TNK buffer (20 mM Tris-HCl, $140 \mathrm{mM} \mathrm{NaCl}, 5 \mathrm{mM} \mathrm{KCl,} \mathrm{pH} \mathrm{7.5),}$ 
the fluorescence intensity of SYBR Green I was greatly enhanced after adding SHP, miR-155-THP hybrids, and the mixture of $\mathrm{H} 1+\mathrm{H} 2+\mathrm{H} 3$, respectively. The mixture of three-leg DNAzyme walkers and SHP but without $\mathrm{Mg}^{2+}$ showed the maximum fluorescence intensity. The reason is that with the increase in length and number of dsDNA, more and more SYBR Green I could insert into the double helix structure of DNA to produce strong fluorescence signals. However, in the presences of $\mathrm{Mg}^{2+}$, the fluorescence intensity of the mixture of three-leg DNAzyme walkers and SHP obviously decreased, indicating that SHP was cleaved by three-leg DNAzyme walkers into ssDNA with the assistance of $\mathrm{Mg}^{2+}$. Finally, the double helix structures of DNA decreased, which weakened the interaction of SHP with SYBR Green I and decreased the fluorescence intensity.

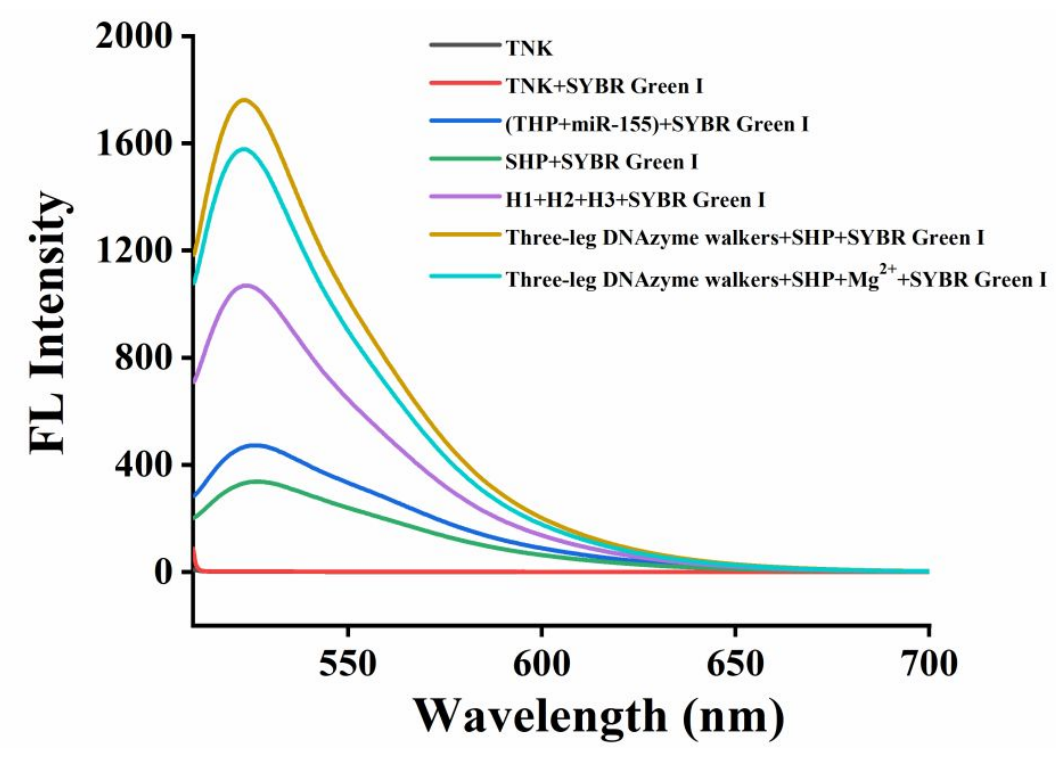

Figure S3. Fluorescence spectra of SYBR Green I at different conditions. The concentration of each type DNA is $0.2 \mu \mathrm{M}$ except SHP is $0.6 \mu \mathrm{M}$. The concentration of miR-155 is $500 \mathrm{pM}$. The concentration of SYBR Green I is diluted by Tris- $\mathrm{HCl}$ buffer solution from $10000 \times$ to $4 \times$. The reaction conditions are same with the experiment section of the manuscript. The excitation wavelength of SYBR Green I is $497 \mathrm{~nm}$, the excitation and emission slit are both $10 \mathrm{~nm}$.

In order to determine the density of SHP on gold electrode, we performed the chronocoulometric (CC) experiment according to the previously reported metod. ${ }^{13-16}$ $\left[\mathrm{Ru}\left(\mathrm{NH}_{3}\right)_{6}\right]^{3+}$ is served as redox marker to compensate the negative charge of oligonucleotides by binding with anionic phosphate of DNA strands in a 
stoichiometric approach. The obtained chronocoulometric curves of $\mathrm{MCH} / \mathrm{SHP}$ modified electrode in the absence and presence of $\left[\mathrm{Ru}\left(\mathrm{NH}_{3}\right)_{6}\right]^{3+}$ are shown in Figure S4. According to the integrated Cottrell expression, the charge $Q$ as a function of time $t$ in CC experiment is shown as follows, ${ }^{13}$

$$
Q=\frac{2 n F A D_{0}^{1 / 2} C_{0}^{*}}{\pi^{1 / 2}} t^{1 / 2}+Q_{d l}+n F A \Gamma_{0}
$$

Where $n$ is the number of electrons per molecule for reduction, $F$ is the Faraday constant (C/eq), $A$ is the electrode area $\left(\mathrm{cm}^{2}\right), D_{0}$ is the diffusion coefficient $\left(\mathrm{cm}^{2} / \mathrm{s}\right)$, $C^{*}{ }_{0}$ is the bulk concentration $\left(\mathrm{mol} / \mathrm{cm}^{2}\right), Q_{d l}$ is the capacitive charge $(\mathrm{C})$, and $\mathrm{nFA} \Gamma_{0}$ is the charge from the reduction of adsorbed redox marker. The surface excess $\left(\Gamma_{0}\right.$, represents the amount of redox marker confined near the electrode surface) is determined from the difference in chronocoulometric intercepts $(t=0)$ in the presence and absence of redox marker (Figure S4). In our experiment, $\Gamma_{0}$ was calculated to be $4.4 \times 10^{-11} \mathrm{~mol} / \mathrm{cm}^{2}$. Under the condition that a complete charge compensation of DNA by redox marker, the saturated surface excess of redox marker can be converted to DNA probe surface density using the following equation, ${ }^{13}$

$$
\Gamma_{D N A}=\Gamma_{0}(\mathrm{Z} / m)\left(N_{A}\right)
$$

where $\Gamma_{\mathrm{DNA}}$ is the probe surface density (molecules/ $\left.\mathrm{cm}^{2}\right), m$ is the number of bases in the probe DNA, $z$ is the charge of the redox molecule, and $N_{\mathrm{A}}$ is Avogadro's number. Therefore, the density of SHP on electrode surface is calculated to be $1.6 \times 10^{12}$ molecules $/ \mathrm{cm}^{2}$. 


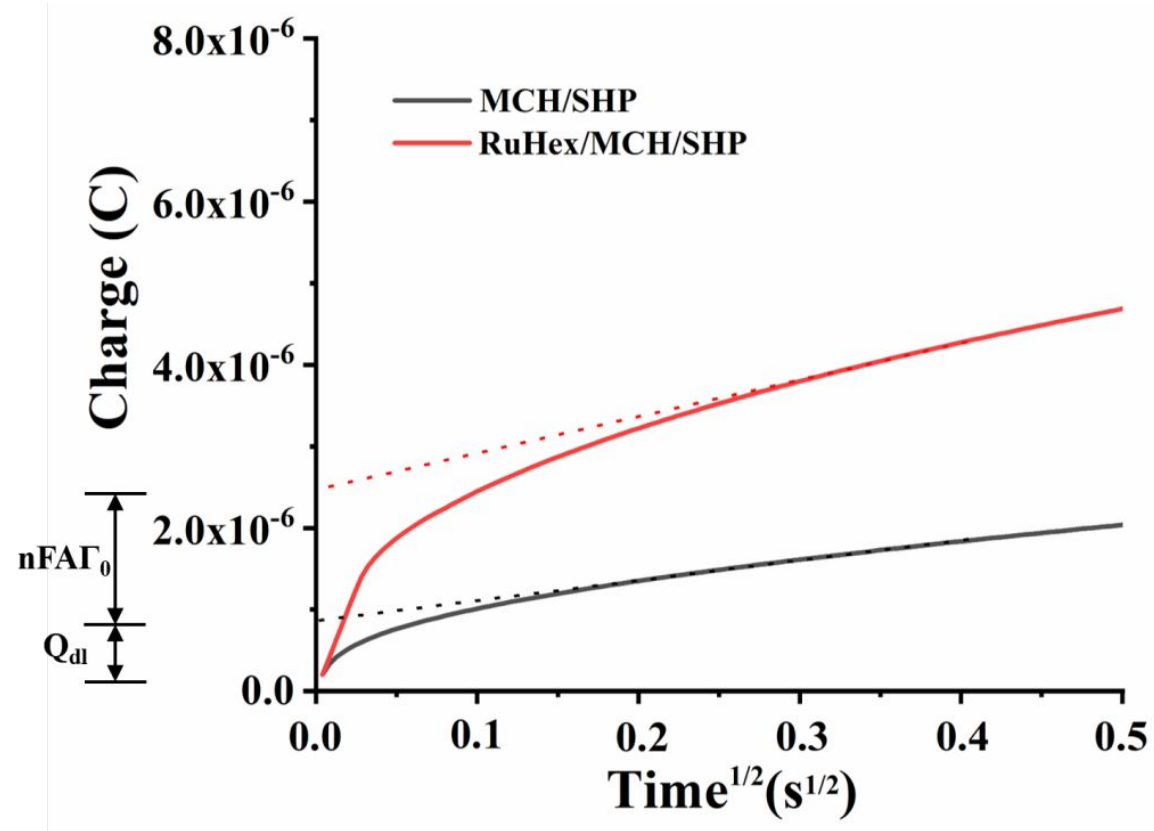

Figure S4. Chronocoulometric response curves for MCH/SHP modified electrode in the absence (black line) and presence of $1.5 \times 10^{-4} \mathrm{M}\left[\mathrm{Ru}\left(\mathrm{NH}_{3}\right)_{6}\right]^{3+}$ (red line). Initial potential: $0.2 \mathrm{~V}$; final potential: $-0.5 \mathrm{~V}$; number of steps: 2 ; pulse width: $0.25 \mathrm{~s}$; sample interval: 0.002 . The measurement buffer is $10 \mathrm{mM}$ Tris $(\mathrm{pH}=7.3)$.

Table S2. Layer parameters for the immobilized layer. (Mean $\pm \mathrm{SD}, \mathrm{n}=3$ )

\begin{tabular}{cccc} 
Layer material & Thickness $(\mathrm{nm})$ & Mass $\left(\mathrm{ng} / \mathrm{mm}^{2}\right)$ & Density $\left(\mathrm{g} / \mathrm{cm}^{3}\right)$ \\
\hline $0.4 \%$ GA & $0.148 \pm 0.00737$ & $0.114 \pm 0.001$ & $0.773 \pm 0.0316$ \\
SHP & $0.518 \pm 0.0118^{\mathrm{a}}$ & $0.203 \pm 0.00153^{\mathrm{a}}$ & $0.393 \pm 0.00656^{\mathrm{a}}$ \\
& $0.152 \pm 0.00764^{\mathrm{b}}$ & $0.0844 \pm 0.007^{\mathrm{b}}$ & $0.636 \pm 0.0624^{\mathrm{b}}$ \\
$\begin{array}{c}\text { Three-leg DNAzyme } \\
\text { walkers }\end{array}$ & & & \\
\hline
\end{tabular}

a Thickness, mass, and density of the whole SHP/GA layer, ${ }^{b}$ thickness, mass, and density of the SHP/GA layer after incubating with three-leg DNAzyme walkers. 
Table S3. Comparison of various biosensors for detection of target nucleic acids.

\begin{tabular}{|c|c|c|c|c|}
\hline Technique & Amplification strategy & Linear range & LOD & Ref. \\
\hline Fluorescence & Exonuclease III & $40 \mathrm{pM}-150 \mathrm{pM}$ & $14 \mathrm{pM}$ & {$[1]$} \\
\hline Colorimetry & DNA machine & $0.2 \mathrm{nM}-120 \mathrm{nM}$ & $0.2 \mathrm{nM}$ & {$[2]$} \\
\hline SPR & RCA and AuNPs & $1.0 \mathrm{pM}-10 \mathrm{nM}$ & $5.0 \mathrm{pM}$ & {$[3]$} \\
\hline ECL & MNAzyme & $50 \mathrm{pM}-1000 \mathrm{nM}$ & $50 \mathrm{pM}$ & {$[4]$} \\
\hline SWV & $\begin{array}{c}\text { RNA-DNA } \\
\text { antibodies/conducting } \\
\text { polymer }\end{array}$ & $1.0 \mathrm{fM}-1.0 \mathrm{nM}$ & $5.0 \mathrm{fM}$ & {$[5]$} \\
\hline DPV & $\begin{array}{c}\text { 3D DNA stem-loop } \\
\text { probe/ferrocene }\end{array}$ & $100 \mathrm{pM}-1.0 \mu \mathrm{M}$ & $10 \mathrm{pM}$ & {$[6]$} \\
\hline Fluorescence & CHA/AgNCs & $200 \mathrm{pM}-20 \mathrm{nM}$ & $200 \mathrm{pM}$ & {$[7]$} \\
\hline DPV & $\begin{array}{c}\text { Potential modulated } \\
\text { cascade of CHA-RCA }\end{array}$ & $15 \mathrm{fM}-250 \mathrm{pM}$ & $13.5 \mathrm{fM}$ & [8] \\
\hline SWV & $\begin{array}{c}\text { Peptide nucleic acid } \\
\text { probe/polyaniline/ } / \mathrm{H}_{2} \mathrm{O}_{2}\end{array}$ & $5.0 \mathrm{fM}-2.0 \mathrm{pM}$ & $2.0 \mathrm{fM}$ & [9] \\
\hline DPV & THP/TSDR & $5.0 \mathrm{fM}-100 \mathrm{pM}$ & $0.27 \mathrm{fM}$ & $\begin{array}{l}\text { This } \\
\text { work }\end{array}$ \\
\hline
\end{tabular}

* LOD: limit of detection, SWV: square wave voltammetry, DPV: differential pulse voltammetry, SPR: surface plasmon resonance, ECL: electrochemiluminescence, RCA: rolling circle amplification, CHA: catalytic hairpin assembly. 


\section{Reference}

[1] Zeng, Y.; Wan, Y.; Zhang, D.; Qi, P. Talanta 2015, 132, 59-64.

[2] Li, H. L.; Ren, J. T.; Liu, Y. Q.; Wang, E. K. Chem. Commun. 2014, 50, 704-706.

[3] Xiang, Y.; Deng, K.; Xia, H.; Yao, C. Y.; Chen, Q. H.; Zhang, L. Q.; Liu, Z. Y.;

$\mathrm{Fu}$, W. L. Biosens. Bioelectron. 2013, 49, 442-449.

[4] Jie, G. F.; Qin, Y. Q.; Meng, Q. M.; Wang, J. L. Analyst 2015, 140, 79-82.

[5] Tran, H. V.; Piro, B.; Reisberg, S.; Duc, H. T.; Pham, M. C. Anal. Chem. 2013, 85, 8469-8474.

[6] Liu, S.; Su, W.; Li, Z.; Ding, X. Biosens. Bioelectron. 2015, 71, 57-61.

[7] Gu, J. Q.; Qiao, Z. Z.; He, X. X.; Yu, Y. R.; Lei, Y. L.; Tang, J. L.; Shi, H.; He, D. G.; Wang, K. M. Analyst 2020, 145, 5194-5199.

[8] Wang, S.; Lu, S. S.; Zhao, J. H.; Ye, J.; Huang, J. S.; Yang, X. R. Biosens. Bioelectron. 2019, 126, 565-571.

[9] Peng, Y.; Yi, G.; Gao, Z. Chem. Commun. 2010, 46, 9131-9133.

[10] He, J. L.; Zhang, Y.; Mei, T. T.; Tang, L.; Huang, S. Y.; Gao, Z. Biosens. Bioelectron. 2019, 144, 111692.

[11] Singer, V. L.; Lawor, T. E.; Yue, S. Mutat. Res. 1999, 439, 37-47.

[12] Xiang, D. S.; Zhou, G. H.; Luo, M.; Ji, X. H.; He, Z. K. Analyst 2012, 137, 3787-3793.

[13] Steel, A. B.; Herne, T. M.; Tarlov, M. J. Anal. Chem. 1998, 70, 4670-4677.

[14] Rant, U.; Arinaga, K.; Fujita, S.; Yakoyama, N.; Abstreiter, G.; Tornow, M. Langmuir 2004, 20, 10086-10092.

[15] Wang, J.; Zhang, S. J.; Zhang, Y. Z. Anal. Biochem. 2010, 396, 304-309.

[16] Dong, X.; Lu, X. C.; Zhang, K. Y.; Zhang, Y. Z. Microchim. Acta 2013, 180, 101-108. 